\title{
PARTICIPACIÓN CIUDADANA A TRAVÉS DEL USO SOCIAL DE LAS TIC EN ESCUELAS DE FAMILIA EN LOS COLEGIOS CATÓLICOS DE MARACAIBO, ESTADO ZULIA, VENEZUELA
}

\section{Citizen Participation through Social Use of ICT in Catholic Schools in Maracaibo, Zulia State, Venezuela}

\section{Participação cidadã através do uso social das TIC em Escolas de Família nas escolas católicas de Maracaibo, estado Zulia, Venezuela}

SALCEDO, Cenys. Universidad Católica Cecilio Acosta (Venezuela)

cenysalcedo@gmail.com

PÁEZ, Ángel. Universidad del Zulia (Venezuela)

aepaezmoreno@gmail.com

\section{Fecha de recibido: 2 de mayo de 2014}

Fecha de aceptado: 10 de febrero de 2015

\section{RESUMEN}

El pensamiento social y el paradigma humanístico en tiempos de la Sociedad de los Saberes han generado transformaciones en las instituciones públicas y privadas, provocando la difusión de conocimiento dentro de sus estructuras con el propósito de alcanzar la meta del buen vivir. La investigación plantea como objetivo analizar la participación ciudadana a través de las TIC en las Escuelas de Familia en los colegios católicos de Maracaibo, estado Zulia. Se utilizó una metodología exploratorio-descriptiva, de campo, no experimental transeccional. La población estuvo constituida por 2088 padres y representantes de los colegios católicos: Instituto Niños Cantores del Zulia, U.E. Colegio La Merced, Unidad Educativa Hermana Elda Estrada Foster y Unidad Educativa Colegio 
Gonzaga, generando una muestra de 466. Los resultados revelaron que la mayor participación de los padres y representantes se manifestó en el nivel informativo, aun cuando se involucran en actividades no pertinentes a la organización que les agrupa. Se observó presencia poco significativa en el ejercicio de toma de decisiones, control y ejecución de actividades, alejándose de la posibilidad de promover un cambio social para construir una mejor sociedad.

Palabras clave: Uso de las TIC, participación ciudadana, cambio social, Escuela de Familia.

\begin{abstract}
The social thought and the humanistic paradigm in times of the Knowledge society have generated transformations in public and private institutions, causing the diffusion of knowledge within its structures in order to achieve the goal of well being. This research proposes to analyze citizen participation through ICT in Family Schools in Catholic schools in Maracaibo, Zulia state. A non-experimental, descriptive, exploratory and transeccional field methodology was used. The population consisted of 2088 parents and representatives of Catholic schools: Instituto Niños Cantores del Zulia, U.E. Colegio La Merced, Unidad Educativa Hermana Elda Estrada Foster y Unidad Educativa Colegio Gonzaga, generating a sample of 466 . The results revealed that greater involvement of parents and representatives stated in the informative level, even though they engage in activities not relevant to the umbrella organization where they belong. Insignificant presence was noted in the exercise of decision making, control and execution of activities, moving away from the opportunity to promote social change and build a better society.
\end{abstract}

Keywords: ICT use, citizen participation, social change, Family School.

\title{
RESUMO
}

O pensamento social e o paradigma humanístico em tempos da Sociedade dos Saberes têm gerado transformações nas instituições públicas e privadas, provocando a difusão de conhecimento dentro de suas estruturas com o propósito de alcançar a meta da boa vida. A pesquisa apresenta como objetivo analisar a participação cidadã através das TIC nas Escolas de Família nas escolas católicas de Maracaibo, no estado Zulia. Utilizou-se uma metodologia exploratório-descritiva, de campo, não experimental transeccional. A população esteve constituída por 2,088 pais e representantes das escolas católicas: Instituto Niños Cantores del Zulia, U.E. Colegio La Merced, Unidad Educativa Hermana Elda Estrada Foster e Unidad Educativa Colegio Gonzaga, gerando uma amostra de 466. Os resultados revelaram que a maior participação dos pais e representantes se manifestou no nível informativo, ainda quando involucraram-se em atividades não pertinentes à organização que agrupa-lhes. Observou-se presencia pouco significativa no exercício de toma de decisões, controle e execução de atividades, afastando-se a possibilidade de promover uma mudança social para construir uma melhor sociedade.

Palavras-chave: Uso das TIC, participação cidadã, mudança social, Escola de Família. 


\section{Introducción}

La sociedad se enfrenta a constantes cambios demandados por las nuevas tendencias globalizantes, dando origen a transformaciones sociales, políticas, culturales, económicas, ambientales y tecnológicas, entre otras, que obligan a la adopción de transformaciones profundas en diferentes ámbitos; entre ellos en el modo de pensar y actuar individualmente, en los miembros de la familia, de las organizaciones, de las naciones, de la humanidad; lo cual impulsa a construir un todo, pasar a formar parte de un todo.

A tal efecto, la generalización de las tecnologías en los hogares y, de forma simultánea, el rechazo o preocupación de los miembros progenitores de la unidad familiar son dos de las principales manifestaciones de la realidad tecnologizada que está imponiendo las demandas, necesidades y estilos de vida (Hernández \& Solano, 2006).

En estas circunstancias, por el desarrollo acelerado que han tenido las TIC, es imposible pensar que los padres y representantes miembros de las Escuelas de Familia, organizaciones donde se genera una cultura de reflexión social y desarrollo humano sostenido, puedan seguir trabajando de forma manual o mecánica. Molina \& Amela (2009) estiman que la sociedad de hoy exige la formación de personas capaces de comprender e interactuar con el mundo en el que están inmersos, apoyado por las novedosas herramientas tecnológicas.

Por consiguiente, se desarrolla la idea de educar a los padres de acuerdo con las condiciones del momento histórico-social, del progreso científico y del desarrollo industrial, por cuanto de esta depende el impulso formativo y social de los hijos, quienes conforman la nueva sociedad (García, 2009). Destaca que la experiencia ha demostrado que los padres son los primeros agentes educativos que pueden motivar a sus hijos, ofreciéndoles espontáneamente afecto, seguridad y ejemplo. Así, ellos adquieren su propia identidad y el desarrollo de su personalidad conforme al equilibrio y conveniencia social.

Los desafíos de la Sociedad de los Saberes en las Escuelas de Familia implican la integración de sus objetivos generales con los de sus miembros en procura de una mejor calidad de vida, y experimentar con las Tecnologías de Información y Comunicación (TIC) es un atributo condicionante sine qua non para ponerse a tono con las transformaciones de la sociedad. Es decir, se requiere estar en contacto con la realidad de un mundo globalizado caracterizado por girar en torno a las novedosas tecnologías, ya que de ellas depende, en gran parte, el futuro desarrollo del país, lo que lleva a establecer los niveles de apropiación tecnológica a partir de su uso e identificar los procesos comunicacionales que sustentan las relaciones de participación.

Lo anteriormente expuesto está en completa relación con los nuevos cambios que mueven al mundo. Un ejemplo lo refiere la estructura de la educación bolivariana orientada en la nueva relación Estado-Sociedad: el Gobierno emite la resolución 752, a través del Ministerio del Poder Popular para la Educación (2005), encargado de presentar las líneas de acción para la creación de las Escuelas para la Familia.

En este mismo orden de ideas, se describe la finalidad del Sistema de Educación Bolivariano de Venezuela (SEB, 2007), la cual muestra que para concretar sus fines e ideales, la institución educativa debe ser un espacio para las TIC. Además se inserta en el Proyecto Nacional Simón Bolívar (PNSB), en el área Tecnologías de la Información considerada como prioritaria en el Plan de Ciencia y Tecnología 2005-2030, adaptándose a las Necesidades de Investigación 2011: Política y Sociedad/Procesos socio-políticos/Apropiación comunitaria de la ciencia y la 
tecnología/Papel de las tecnología de información y comunicación en el desarrollo de la democracia participativa y protagónica.

Se trata entonces de abordar la Participación ciudadana a través de las TIC en las Escuelas de Familia en los Colegios católicos de Maracaibo, estado Zulia, como vehículo capaz de potenciar la participación como parte del proceso de cambio y transformación para el desarrollo humano y una mejor calidad de vida, además como experiencia altamente significativa, donde la teoría y la práctica no tienen fronteras y pueden facilitar la aplicación de estrategias metodológicas abiertas y flexibles que, desarrolladas con un sentido de proceso de complejidad creciente, contribuirán a formar padres y madres críticos, creativos, reflexivos, que produzcan cambios paradigmáticos hacia la elaboración de conocimiento.

El estudio se desarrolló profundizando la participación de acuerdo a la estructura de los cinco niveles definidos por la Contraloría Social del Estado de Guanajuato, México (2006), a saber: información, consulta, decisión, control y ejecución desde las comunidades virtuales en provecho de sus miembros, la escuela y la misma organización que los agrupa, para generar escenarios de aprendizaje e intercambio de conocimiento.

En ese mismo orden, complementado por Macías (2009) al estimar que existe participación en la medida que hay presencia activa de cada hombre en la toma de decisiones para la construcción de una sociedad. Supone una visión de transformación y perfeccionamiento de la misma a través de una promoción del cambio social. Mientras Albornoz (2007) considera que la participación ciudadana está dando sus primeros pasos hacia la e-participación, delineando características y exigencias propias, gracias a la iniciativa oportuna, tanto en lo referente al acceso, a la conectividad y al empoderamiento de las herramientas tecnológicas.

\subsection{La Sociedad de los Saberes}

En Venezuela hay quienes todavía se preguntan si en realidad la población ha entrado en la tan famosa Era de la Información (o del Conocimiento, o de los Saberes), ya que si bien una parte de la población tiene acceso tanto a los productos y aparatos informacionales o comunicacionales tradicionales (como los libros, revistas y programas de TV especializados) como a los digitales (e-books, bases de datos, e-learning, a través de Internet), para nadie es un secreto que la mayor parte de la población apenas logra llenar algunas necesidades básicas.

En contraste, también es cierto que las diferencias de acceso a la información entre estratos pobres y ricos siempre ha existido en todas las sociedades y que Venezuela no escapa a las presiones de la sociedad globalizada cuyas relaciones sociales, económicas y educativas se dan fundamentalmente a través de las redes telemáticas. Un análisis publicado en Tendencias Digitales (2012) refleja que los hombres se conectan más a la Internet (54\%), mientras que las mujeres lo hacen en un $46 \%$. La mayoría de ellos se encuentran ubicados en el estrato D (35\%) y E (36\%), sumando $71 \%$ del total de usuarios, mientras AB representa el $4 \%$ y C el $26 \%$.

En este sentido, Venezuela ha asumido el concepto de Sociedad de los Saberes como una política de Estado y ello se manifiesta en la Misión Ciencia. El gran desafío de la Misión Ciencia está en la posibilidad de recuperar saberes alternativos, necesarios para contrarrestar el "peso de la hegemonía cultural de las élites, de los modos de hacer de grupos y comunidades en todos lados, es decir, la reapropiación de un 'capital cultural' que es consustancial a un verdadero proceso de inclusión de prácticas y saberes marginalizados por la lógica de la dominación" (Lanz, 2006). 
Desde el mundo organizacional, se hace entonces imperante una visión balanceada sobre la sociedad del conocimiento. En un lado de la balanza se tiene una visión sobre la Economía del Conocimiento, como un sistema basado en el poder despótico que usa la tecnología para imponer conductas sociales segmentadas sobre una superficie homogénea con una dinámica en la cual, mientras más libre sea el individuo para afirmar su soberanía como intercambiante, de bienes, servicios y de ideas, tanto más consolidado se vuelve el poder despótico (Del Búfalo, 2005). En el otro, las enormes posibilidades de la Sociedad de los Saberes, como un contexto en el que las TIC son una eficaz herramienta de apropiación del conocimiento.

\subsection{Participación ciudadana}

El discurso participativo, el reconocimiento efectivo de la consulta y la participación ciudadana afianzan una evolución importante, trascendente y sustentable en las instituciones. En el caso que atañe a la investigación, la participación de los padres y representantes se remite a dos espacios de relevancia: uno interno, el de la institución escolar, en el ámbito de la política educativa, y otro externo a la comunidad, la participación de las Escuelas de Padres o Escuelas de Familia, al margen de líneas políticas oficiales o gubernamentales, en la búsqueda de una mejor calidad de vida.

Según Merino (1996), citado en Guillen et ál. (2009), la participación ciudadana como un hecho social significa: "Intervenir en los centros de gobiernos de una colectividad, participar en sus decisiones de la vida colectiva, de la administración de sus recursos, del modo como se distribuyen sus costos y beneficios" (p. 180). Por consiguiente, la participación ciudadana como parte del proceso de cambio y transformación, es parte envolvente de la revolución tecnológica que se encamina hacia una ciudadanía más informada y participativa, lo cual se traduce en un mejoramiento directo de su calidad de vida para coadyuvar al desarrollo humano.

La presente investigación asume la participación ciudadana a través de las Tecnologías de la Información y la Comunicación como una autopista virtual que promoverá la participación, donde sin intermediarios de ningún tipo los ciudadanos pueden comunicarse entre sí y la organización, es decir, puede haber reciprocidad, con consultas públicas navegando en la red, sin que esta se convierta en sustituto sino en un valor agregado que auxilie el proceso de aprendizaje y conocimientos para una mejor calidad de vida.

De allí pues que, para profundizar la participación ciudadana a través de las tecnologías de información y comunicación, el investigador asume los criterios reflejados en el Informe de la Contraloría Social del estado de Guanajuato, Estado de México, titulado Programa estatal de Contraloría Social 2005-2006 (2006, p. 23), donde se estructuran cinco niveles de participación ciudadana:

En la información: la población tiene derecho a ser informada sobre los asuntos públicos, de lo contrario, no podría comprometerse efectivamente si no conoce sobre el tejido público de su comunidad local, regional o nacional.

En la consulta: es el derecho a ser consultados, todos aquellos que pueden resultar afectados - directa o indirectamente- por una decisión gubernamental.

En la decisión: es el derecho de participar en la formación final de la voluntad que determinará un curso de acción específico. Generalmente ese nivel de profundidad lo debería ejercer la autoridad, previa información y 
consulta a la ciudadanía afectada. Sin embargo, para decisiones de mayor magnitud, es conveniente que la responsable de tomar la decisión sea la población.

En el control: es el derecho de los ciudadanos a ejercer acciones de fiscalización social sobre la gestión pública. Ya que, una vez tomada la decisión, se requiere también de mecanismos que permitan la verificación del cumplimiento de la decisión adoptada.

En la ejecución: este es un ámbito de profundidad que merece un delicado análisis, ya que si proviene de un proceso de formación de voluntad concertado, mediante los niveles anteriores, es entonces un salto cualitativo importante en la plenitud de la participación.

Resulta claro que la participación ciudadana confluye de un acto social colectivo a través del cual se contemplan dos elementos complementarios, que son: la influencia de la sociedad sobre el individuo, pero, sobre todo, la voluntad personal de influir en la sociedad (Pitalúa, 2008).

De esta manera, muchos han de recibir apoyo por parte de los demás, y las Escuelas de Familia deben potenciar el acceso, uso y disfrute de los recursos tecnológicos para fomentar su participación en la vida cultural, educativa, social y política, donde la integración como proceso dinámico incluye la intervención de todos los miembros de la sociedad basado en la igualdad, no en la caridad.

La propuesta de cinco niveles de participación surgida de la Contraloría Social del Estado de Guanajuato (2006), marcan la pauta a la presente investigación. En el nivel informativo, se provee información sobre derechos, responsabilidades y opciones; los miembros de las Escuelas de Familia tienen el derecho a ser informados de todos los asuntos públicos y privados, son un gran puente para crear pautas de convivencia desde lo local hasta romper fronteras. En el segundo nivel, los ciudadanos son invitados a opinar, a ser consultados de aquello que afecta sus intereses particulares así como el de de las organizaciones, donde se involucran los padres, los hijos y la escuela.

El tercer nivel que se adapta a la investigación es el de la decisión, donde padres, madres y representantes participan en la definición del curso de sus acciones. Los directivos ejercen la autoridad, previa información y consulta a los miembros integrantes de la Escuela de Familia, sin embargo, las decisiones de gran magnitud las toman los miembros en pleno. De la misma forma, la decisión puede estar influenciada por representantes o ciudadanos que forman parte de otros órganos directivos o consultivos, la asociación y el poder.

En el nivel de control (cuarto), los miembros ejercen acciones de fiscalización social sobre la gestión de directivos, lo que verifica el cumplimiento de las actividades acordadas y recursos que se manejen. Los ciudadanos administran el programa o el curso de acción. Por su parte, el nivel ejecución, se convierte en el salto cualitativo de la participación en el uso social de las tecnologías de la información y comunicación, teniendo como piso los niveles anteriores, durante los cuales se logra un proceso de formación de voluntades concertadas. Los ciudadanos ejercen el poder de participar en el proceso de toma de decisiones o ejecución.

\subsection{Uso social de las TIC}

En una publicación anterior (Salcedo \& Páez, 2013) decíamos que la inclusión social es clave para imprimirle sostenibilidad a toda organización, pues en la medida en que se le brinden las posibilidades; se acepten sus ideas de 
cambio; se respeten sus derechos, y se ofrezca ayuda, protección, orientación y educación, se fortalece el desarrollo integral de las comunidades.

Vásquez (2002) considera que el uso de las TIC implica conocerlas y emplearlas para diversas tareas. Estas tecnologías expanden las posibilidades de la comunicación, generan nuevas culturas y posibilitan el desarrollo de nuevas habilidades y formas de construcción del conocimiento. Además, estima necesario conocer y comprender en profundidad el uso que realizan las personas de estas tecnologías, cómo las utilizan, para qué y con qué frecuencia lo hacen, así como la importancia que tienen en la vida cotidiana.

Para Tissen (2005) las TIC constituyen una respuesta a las necesidades de la sociedad. Su rol se centra en las actividades informacionales de todos los individuos que de una u otra forma utilizan sus capacidades técnicas para sintetizar las funciones que anteriormente eran tratadas de manera manual, visualizando como eje central de su progreso la sistematización técnica de la información y el conocimiento.

Sánchez (2008) señala que el uso social de las tecnologías apunta hacia la utilización con sentido de las TIC, así como saber combinarlas con otras formas de comunicación social, que incluya la producción de contenidos propios, o bien, de acceder a contenidos de otros que resulten útiles. Agrega, que las TIC deben aprovecharse para el desarrollo integral de una comunidad, con visión integral de desarrollo, y sobre todo, que impulse el potencial humano en sus diferentes dimensiones para afianzar así la prosperidad económica, pero con equidad, y el fortalecimiento democrático con transparencia y justicia social.

Evidentemente las TIC optimizan el manejo de la información y el desarrollo de la comunicación. Permiten actuar sobre la información y generar mayor conocimiento e inteligencia. Abarcan todos los ámbitos de la experiencia humana. Están en todas partes y modifican los espacios de la experiencia cotidiana: el trabajo, las formas de estudiar, las modalidades para comprar y vender, los trámites, el aprendizaje y el acceso a la salud, entre otros.

Hoy, el uso de las Tecnologías de Información y Comunicación está ampliamente extendido, ocasionando transformaciones en todos los ámbitos de la sociedad. Kranzberg (1985), en su ley sobre la relación entre tecnología y sociedad señala que la tecnología no es buena ni mala ni tampoco neutral; pero esta relación no debe entenderse como una relación fatalista y determinista, sino como una relación que conduce a nuevas situaciones y planteamientos orientados a la investigación y el análisis de sus efectos, a tomar posiciones que marquen el camino y la dirección a seguir atendiendo a la sociedad ideal.

Es aquí donde marca un papel importante el impacto social de las TIC, haciendo sentir la fuerza e influencia que tiene en los diferentes ámbitos y las nuevas estructuras sociales que están surgiendo, produciéndose una interacción constante entre la tecnología y la sociedad. Es necesario que la sociedad analice los cambios y las consecuencias sociales que derivan del uso de las TIC, de modo que atienda las necesidades sociales y culturales de las personas, donde la punta de lanza sea la igualdad y el respeto a los derechos humanos.

El aporte de los actores, en el impulso de actividades que impliquen el uso social de las tecnologías para promover espacios de información referida a la participación ciudadana a través de las TIC, resulta fundamental para mejorar la apropiación de los contenidos, la calidad de las estrategias comunicacionales y el fortalecimiento de vínculos intergeneracionales.

Enuncia Mas (2007, p. 164) que "el papel protagónico de las TIC en la sociedad actual las convierte en un factor fundamental para el mejoramiento de la calidad de vida"; en el contexto de las Escuelas de Familia, propicia a la 
creación de espacios de integración y participación que conlleva a la multiplicación del conocimiento, a la generación de proyectos sociales que contribuyan a una mejor calidad de vida.

Entonces, es pertinente que los miembros integrantes de las Escuelas de Familia hagan uso adecuado de las tecnologías, que los ubique en el ámbito de los cambios que se mueven en la sociedad, además de emplearlas como una herramienta para la concienciación, para la participación ciudadana y la generación de conocimiento. También se agrega la difusión y gestión de los proyectos para la escuela y su propia comunidad; sin duda, aplicando la contraloría social para evaluarlos y vigilar a quienes en ellos se involucren, lo que indica el manejo de políticas públicas desde el conocimiento de la Constitución Nacional y todos los elementos jurídicos que le involucren.

\subsection{Las Escuelas de Familia (EF) y las TIC}

En una publicación anterior (Salcedo \& Páez, 2013) decíamos que las Escuelas de Familia aparecieron hace bastantes años, con diversas formas y estilos. Después de un cierto período, han vuelto a surgir voces e instancias reclamando su puesta en marcha y su renovación. Se invoca su necesidad urgente. Examinando las expresiones de esta demanda, se perciben nuevas motivaciones y el deseo de involucrarse en esta común actividad.

Se mira a las Escuelas de Padres marcada por un solo género, y la carga de responsabilidad en un solo sentido, ante esa situación se busca la integración de todos los que componen la familia y desde el Reglamento General de la Ley Orgánica de Educación (1999) en varias partes se estimula la incorporación de la familia para que participe activamente en el proceso educativo.

Por su parte el artículo $22^{\circ}$, numeral 6, de la resolución 572, del Ministerio Popular para la Educación (2005), aún sin publicarse en Gaceta Oficial, crea esa organización en las instituciones escolares de Venezuela, bajo la denominación "Escuela para la Familia" como una alternativa de formación para fortalecer y elevar los valores, y propiciar la integración Escuela-Familia-Comunidad. Complementa el artículo 51 del mismo texto legal, todo en cuanto al proceso de desarrollo educativo de la Comunidad Educativa Bolivariana (CEB) en el contexto de la formación ciudadana, en el marco del desarrollo endógeno, local, regional y nacional.

En la página web Escuela de Familia (s.f.) se describe:

Una escuela de familia es un centro donde se genera una cultura de reflexión social y desarrollo humano sostenido, con la implementación de programas de entrenamientos focales orientados hacia la toma de conciencia y preservación de los valores primarios de la vida y capacitación en habilidades prácticas que permitan a la familia generar los recursos que necesita para su sustentación y desarrollo socio-moral, espiritual, cultural y económico.

Desde esa perspectiva, la sociedad de hoy exige la formación de personas capaces de comprender e interactuar con el mundo en el que están inmersos, y dentro del contexto familiar y social, con todo tipo de artefactos tecnológicos, pasando inevitablemente por el televisor y los videojuegos, hasta llegar a la computadora personal y sus redes de información.

Sin embargo, Gutiérrez (1997) dijo:

Hemos de capacitarlos para que puedan acceder a esos medios pero también deben aprender a ser críticos con los mismos. Únicamente desde el conocimiento de los mismos se puede llegar a analizarlos y valorarlos en su justa medida, atendiendo a sus ventajas pero también a sus inconvenientes. No se trata 
de educar para un uso y consumo de los medios de acuerdo a las leyes del mercado y a las imposiciones de una globalización discriminatoria, sino de dar pautas para el análisis de medios, productos e ideologías, así como propuestas alternativas de utilización de las nuevas tecnologías multimedia desde posturas críticas y comprometidas. (Gutiérrez, 1997, p.12)

Por su parte Terán (2011) hace una reflexión sobre el uso de las novedosas tecnologías por parte de los miembros de la familia, considera que es un recurso muy importante para obtener información y comunicarse, pero un mal uso de las mismas entraña riesgos considerables. A tal situación agrega que el ordenador, el móvil o los videojuegos no son medios para tener entretenidos a los menores en la casa y así tener mayor tranquilidad. "Si no controlamos su uso, pueden servir también para perder el tiempo, para suspender los estudios, para ponerse en contacto con información dañina o con personas peligrosas para su seguridad".

\section{Metodología}

El presente estudio es de tipo exploratorio-descriptivo de campo con un diseño transeccional en el que se midió la participación ciudadana a través de las TIC en padres y representantes miembros de las Escuelas de Familia de cuatro colegios católicos ubicadas en el municipio Maracaibo, estado Zulia, en un solo período de tiempo.

Por efecto de la variable social interesaba tener grupos sociales que tomaran en cuenta características sociodemográficas de la población objeto de estudio. En ese sentido, basado en el listado de la Asociación Venezolana de Educación Católica (AVEC) y ubicación geográfica de los colegios se escogieron de forma aleatoria dos colegios de clase media/alta y dos de media/baja; definiéndose así la población a la que realmente se tuvo acceso y de la cual se extrae la muestra representativa, quedando constituida en 2088 padres y representantes de cuatro (4) colegios católicos: Instituto Niños Cantores del Zulia y U.E. Colegio La Merced (clase media/alta); Unidad Educativa Hermana Elda Estrada Foster y Unidad Educativa Colegio Gonzaga (clase media/baja).

\section{Tabla 1. Distribución de la población}

\begin{tabular}{|c|c|c|c|}
\hline Colegio & Zona & Estrato & $\begin{array}{l}\text { No. de } \\
\text { representantes }\end{array}$ \\
\hline Instituto Niños Cantores del Zulia & \multirow{2}{*}{ Zona suroeste } & medio/alto & 238 \\
\hline Unidad Educativa Colegio Gonzaga & & medio/bajo & 975 \\
\hline U.E. Colegio La Merced & \multirow{2}{*}{ Zona noreste } & medio/alto & 415 \\
\hline Unidad Educativa Hermana Elda Estrada Foster & & medio/bajo & 460 \\
\hline \multicolumn{3}{|c|}{ Total padres y representantes } & 2088 \\
\hline
\end{tabular}

Fuente: Salcedo (2012). 
Posteriormente, aplicando el programa STATS a la población de 2088 padres y representantes, que constituyen el total de los colegios seleccionados, con un nivel de confianza de $95 \%$, porcentaje estimado de la muestra de $50 \%$ y un margen de error del $4 \%$ se obtiene una muestra de 466 miembros de las Escuelas de Familia.

Tabla 2. Muestreo por cuotas

\begin{tabular}{|c|c|c|}
\hline & Estrato medio/alto & Estrato medio/bajo \\
\hline \multirow{2}{*}{ Zona suroeste } & Niños Cantores del Zulia & Gonzaga \\
& $\mathrm{N}=238$ & $\mathrm{~N}=975$ \\
$\mathrm{n}=53$ & $\mathrm{n}=218$ \\
\hline \multirow{2}{*}{ Zona noreste } & La Merced & Hermana Elda Estrada de Foster \\
& $\mathrm{N}=415$ & $\mathrm{~N}=\mathbf{4 6 0}$ \\
& $\mathrm{n}=92$ & $\mathrm{n}=103$ \\
\hline \multicolumn{2}{|c|}{ Total Muestra $\mathbf{( n ) = 4 6 6}$} \\
\hline
\end{tabular}

Fuente: Salcedo (2012).

Se aplicó la técnica de la encuesta, bajo la modalidad de cuestionario, como instrumento de registro elaborado. En el cuestionario se utilizaron preguntas cerradas y abiertas, dirigidas al usuario para que puedan ser respondidas bajo un esquema de selección simple, donde en ocasiones recogió una o varias opciones, dependiendo de la naturaleza del ítem. El cuestionario abordó las dimensiones acceso, información, consulta, decisión, control, ejecución, correspondientes a los niveles de participación ciudadana. A partir del criterio de Balestrini (1997, p. 140): "Una vez que se ha definido y diseñado los instrumentos y procedimientos de recolección de datos, atendiendo al tipo de estudios de que se trate, antes de aplicarlos de manera definitiva en la muestra seleccionada, es conveniente someterlos a prueba, con el propósito de establecer la validez de estos, en relación al problema investigado"; el instrumento fue observado, evaluado y aprobado por cuatro (04) investigadores expertos en Tecnologías de la Información y la Comunicación, y uno (01) en Metodología, provenientes de la Universidad Católica Cecilio Acosta (UNICA), la Universidad del Zulia (LUZ) y la Universidad Rafael Belloso Chacín (URBE).

\section{Análisis y discusión de los resultados}

La interpretación de los análisis y discusión de los resultados se fundamentaron en un proceso de reflexión crítica y argumentativa, que dio respuesta al propósito de la investigación, el cual se orientó en "Analizar la participación ciudadana a través de las TIC en las Escuelas de Familia en los colegios católicos de Maracaibo, estado Zulia", personificados en 466 padres y representantes tomados del muestreo por cuotas de los cuatro colegios católicos seleccionados: Niños Cantores del Zulia, La Merced, Gonzaga y Hermana Elda Estrada de Foster. 


\subsection{Disponibilidad de infraestructura}

En el indicador disponibilidad de infraestructura se encontró que el 89,8\% cuenta con equipos de comunicación electrónica, un $9 \%$ manifestó no poseer y el 1,2\% no respondió (gráfica 1). La totalidad de la respuesta afirmativa se distribuyó en 41,2\% computadoras, 21,2\% laptop y 37,6\% teléfonos; esto refleja que los consultados disponen del recurso tecnológico comunicacional.

\section{Gráfica 1. ¿Cuenta con equipos para la comunicación electrónica?}

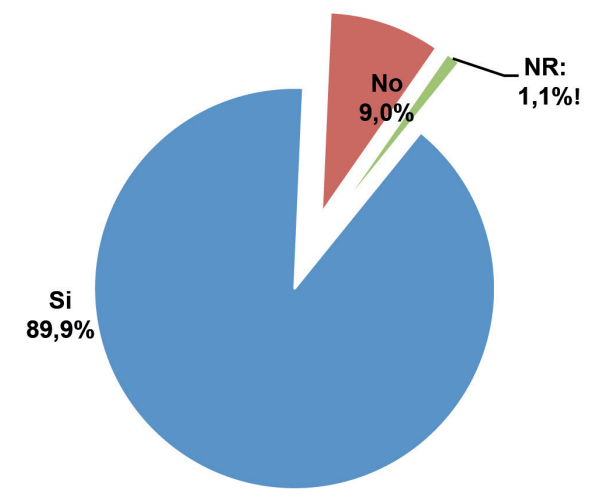

Fuente: Salcedo (2012).

\subsection{Conexión a Internet}

En lo que respecta a la conexión del equipo a Internet el 77,9\% de los consultados se expresaron afirmativamente; el 19,6\% dijo que no, mientras el 2,5\% no respondió (gráfica 2). Basados en 338 respuestas afirmativas de la pregunta anterior, el $51,8 \%$ de los encuestados señalaron que se conectan a Internet a través de la línea telefónica residencial, $45 \%$ por línea telefónica móvil, el 1,8\% por medio de una línea de TV, el 0,9\% otras vías y un 0,6\% manifestó no saber. Indicando que un alto porcentaje buscó de alguna manera tener acceso al servicio de Internet.

\section{Gráfica 2. ¿Conecta su equipo a la Internet?}

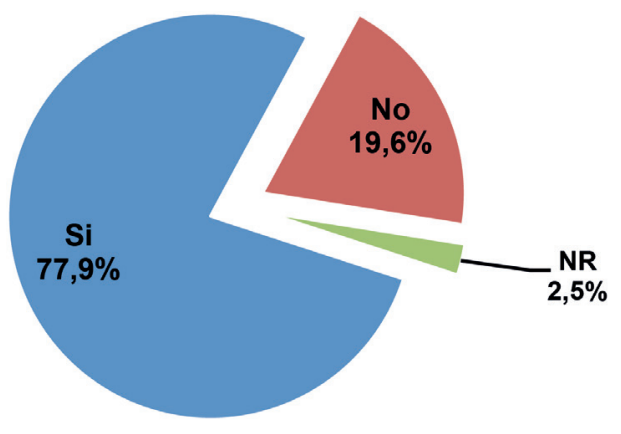

Fuente: Salcedo (2012). 
En respuesta a la interrogante de dónde suelen acceder a la Internet, mayoritariamente se conectaron desde sus casas $(51,8 \%)$ y los centros de trabajo (43,8\%); para los infocentros un bajo porcentaje del $2,1 \%$, mientras que desde los cibercafé y otros sitios, cada uno con el 1,2\%. El resultado demuestra el interés de los usuarios en conseguir alternativas que les permitan acceder a las plataformas digitales bien sea a través de tecnologías de comunicación de carácter público o privado.

El alto porcentaje $(89,8 \%)$ de consultados que cuenta con equipos de comunicación y la multiplicidad de conexión a Internet, según el criterio de Barbero (1987), revela que los ciudadanos agregan a los instrumentos mediadores la participación y la integración social incrementado las posibilidades de sustentabilidad política y experiencias; situación que perfecciona Petrizzo (2005) afirmando que los ciudadanos se involucran consciente y voluntariamente en todos y cada uno de los procesos que directa o indirectamente le afectan para sumir retos en la construcción del conocimiento.

\subsection{Herramientas de comunicación}

Los datos derivados del indicador iniciativas disponibles mostraron el tiempo que utilizan para acceder a las comunicaciones electrónicas, siendo los mayores porcentajes $32 \%$ menos de 30 minutos, 30,9\% de 30 minutos a 1 hora y con $21 \%$ de 1 a 2 horas; con un bajo porcentaje se encuentran de 2 a 3 horas (7,6\%), de 3 a 5 horas (5,1\%) y con más de 5 horas (3,5\%). Se demostró, de acuerdo a los números manejados, que más del $80 \%$ del tiempo empleado por los usuarios en la navegación digital no excede a las 2 horas.

Es importante resaltar que las herramientas utilizadas durante los tiempos empleados se concentran en correos electrónicos y Facebook, $41 \%$ cada uno, evidenciando que constituyen los medios de comunicación digital más usados; distribuyéndose el resto en Twitter (7,6\%), páginas web (6,5\%), otras (2,5\%) (gráfica 3).

\section{Gráfica 3. ¿Cuál de las siguientes herramientas de comunicación utiliza con frecuencia?}

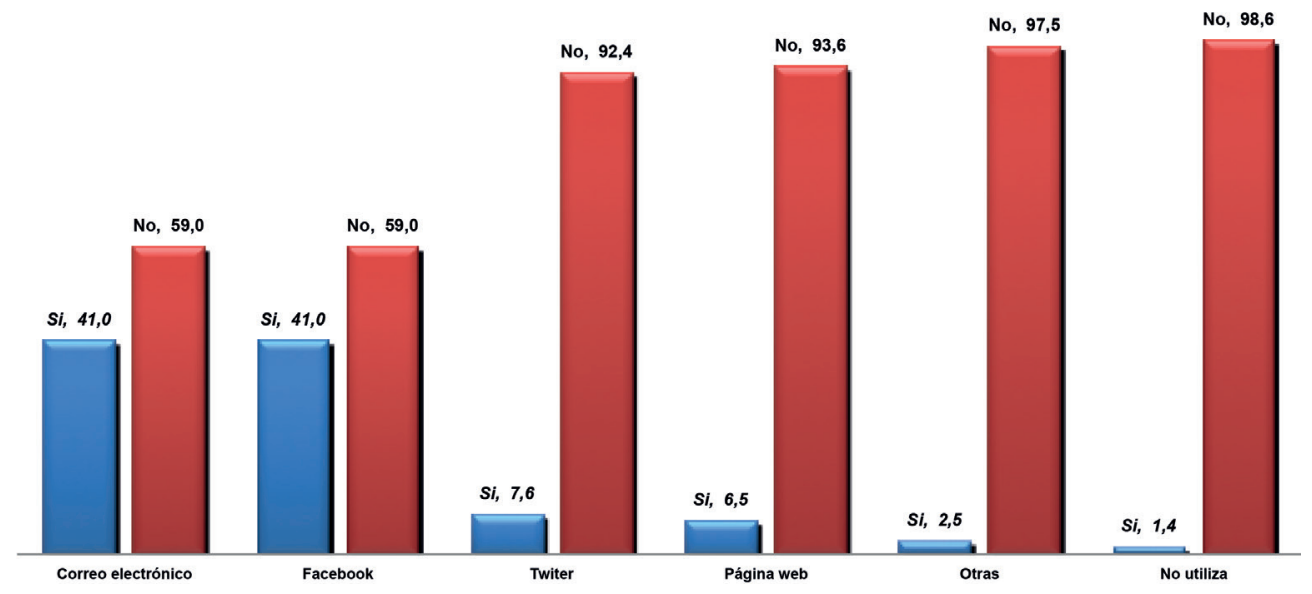

Fuente: Salcedo (2012). 
En ese sentido, cita Albornoz (2007) que la participación ciudadana está dando sus primeros pasos hacia la e-participación, delineando características y exigencias propias. En principio lo está logrando gracias a su propia iniciativa, tanto en lo referente al acceso, a la conectividad y al empoderamiento de las herramientas tecnológicas. De esta manera, muchos han de recibir apoyo por parte de los demás, y las Escuelas de Familia deben potenciar el acceso, uso y disfrute de los recursos tecnológicos para fomentar su participación en la vida cultural, educativa, social y política, donde la integración como proceso dinámico incluye la participación de todos los miembros de la sociedad basado en la igualdad, no en la caridad.

Las relaciones entre el marco teórico diseñado en este enfoque son muy relevantes para determinar el nivel de acceso de los usuarios de las TIC, ya que resulta claro que los ciudadanos del mundo del siglo XXI conviven con fabulosas máquinas y materiales, según lo señalado por Pitalua (2008) la participación ciudadana confluye de un acto social colectivo a través del cual se contemplan dos elementos complementarios que son: la influencia de la sociedad sobre el individuo, pero, sobre todo, la voluntad personal de influir en la sociedad.

Aunque los resultados son favorables con relación al acceso, se detecta una oportunidad en mejorar con relación al comportamiento de este indicador, particularmente en el planteado en el ítem 7, donde los padres y representantes utilizan mayormente el correo electrónico y secundariamente las páginas web, debilitando la posibilidad de abrir puertas a actividades que ayudan al desarrollo personal y entornos multimedia que acercan la realidad al mundo digital y permiten también crear inexistentes realidades virtuales.

\subsection{Información sobre los miembros de las EF}

Para el análisis de la subdimensión nivel informativo, se comenzó con el indicador Información sobre los miembros de las Escuelas de Familia, reflejó que el mayor porcentaje (49,8\%) nunca utilizaron la comunicación digital para desarrollar actividades vinculadas a las Escuelas de Familia, seguido por $29 \%$ que manifestó que a veces; el 11,1\% expresó que siempre y el 10,1\% frecuentemente (gráfica 4).

\section{Gráfica 4. ¿Utiliza la comunicación digital para desarrollar actividades vinculadas} a las Escuelas de Familia?

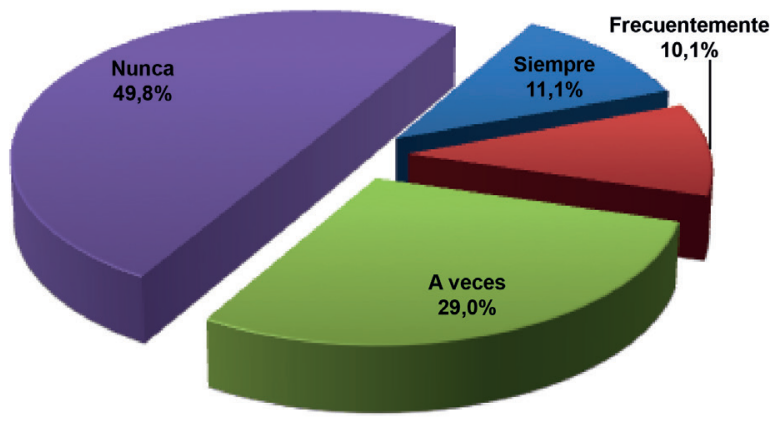

Fuente: Salcedo (2012). 
Partiendo del $100 \%$ de quienes hacen uso de la comunicación digital, se encontró que el 45,2 \% fue para obtener información, el 25,1\% para enviar o recibir correos electrónicos, el 15,9\% accedió a páginas web y el 13,8\%, el menor porcentaje, para tratar con organizaciones gubernamentales $u / o$ autoridades públicas (intercambiar información).

En cuanto al ítem 10 sobre los datos encontrados, los resultados mostraron que 20,3\% obtuvieron números telefónicos, $21,9 \%$, correos electrónicos, $1,8 \%$, direcciones de oficina, $1,15 \%$, otros, y 4,15\% no pudo encontrar información que les permitiera contactar a algún miembro de las Escuelas de Familia. Estos resultados reflejaron que no existe una apropiación tecnológica orientada para el mejor aprovechamiento y participación en las Escuelas de Familia.

\subsection{Disponibilidad de documentos legales}

En el caso del indicador "Disponibilidad de documentos legales", se reveló que cerca a las tres cuartas partes de la muestra $(72,4 \%)$, no buscaron información sobre leyes, decretos, resoluciones o reglamentos venezolanos relacionados a las Escuelas de Familia, el 20,7\% respondió de forma afirmativa y el 6,9\% no encontró (gráfica 5).

\section{Gráfica 5. ¿Encontró información sobre leyes, decretos, resoluciones o reglamentos venezolanos} relacionados a las Escuelas de Familia?

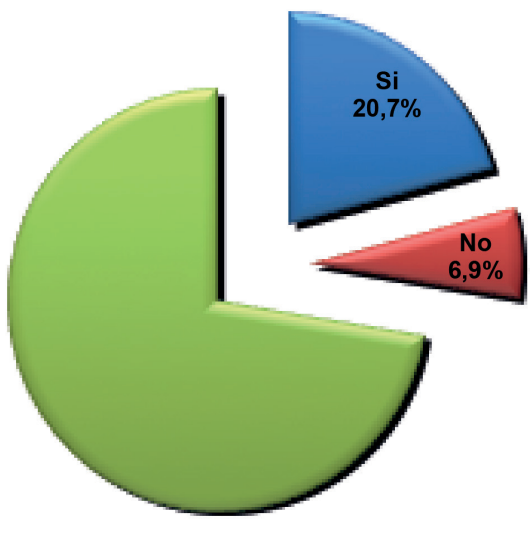

\section{No he buscado}

$$
72,4 \%
$$

Fuente: Salcedo (2012).

Por su parte, los datos encontrados a través de las páginas web, o Internet, permitieron contactar alguna institución sobre la Familia, siendo los más representativos los correos electrónicos con un 19,8\%, seguido de los números telefónicos con 16,8\% y direcciones 10,6\%. 


\subsection{Información sobre las instituciones}

El comportamiento del indicador información sobre las instituciones encontradas en sitios web, o Internet, de entes públicos o privados referente a organismos u organizaciones familiares reveló que más de la mitad de la población muestral $(51,4 \%)$ no ha buscado; el 16,1\% encontró noticias e informaciones, el 14,1\% funcionamiento de la institución, el 7,8\% actividades a ejecutar, el 6,9\% afiliación y el 3,7\% manifestó no encontrar (gráfica 6).

\section{Gráfica 6. ¿Qué información ha encontrada en sitios web, o Internet, de las instituciones públicas} o privadas acerca de organismos u organizaciones familiares?

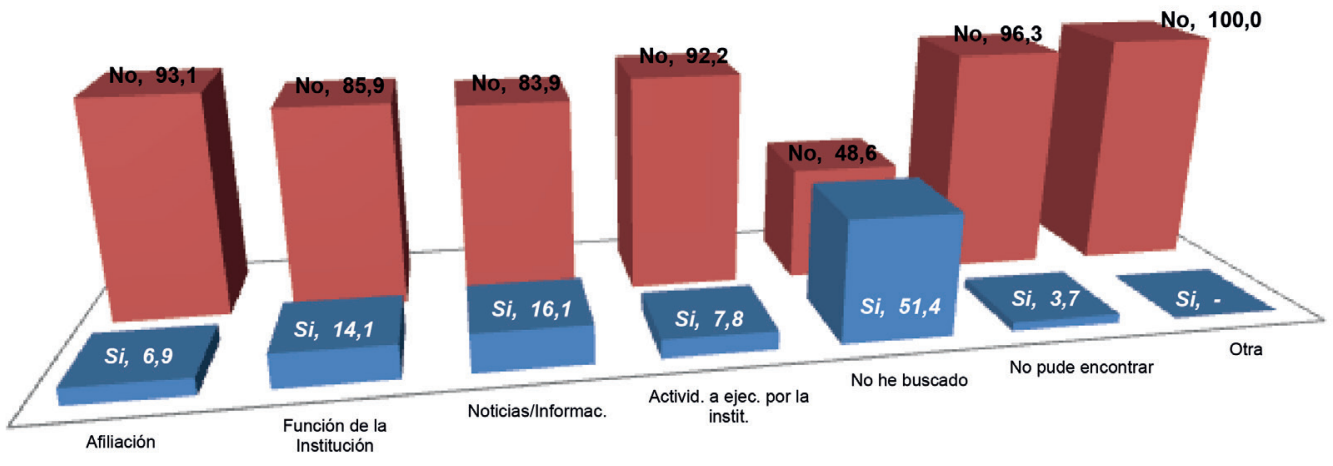

Fuente: Salcedo (2012).

Por su parte, se destaca que la institución a través del cual se encontró mayor información fue la escuela o liceo con el 37,9\%, seguido por el Ministerio del Poder Popular para la Educación con 25,1\%, la AVEC con $18 \%$ y con $12,3 \%$ Pastoral Familiar.

A los efectos de la información hallada sobre las Escuelas de Familia correspondió a los correos electrónicos con el $18 \%$, seguido con $11,5 \%$ por los números telefónicos, $6 \%$ la dirección, $2,5 \%$ fax, 2,3\% otra y el 1,2 no pudo encontrar. Contrariamente se encontró que el 58,5\% no buscó información alguna (gráfica 7). 


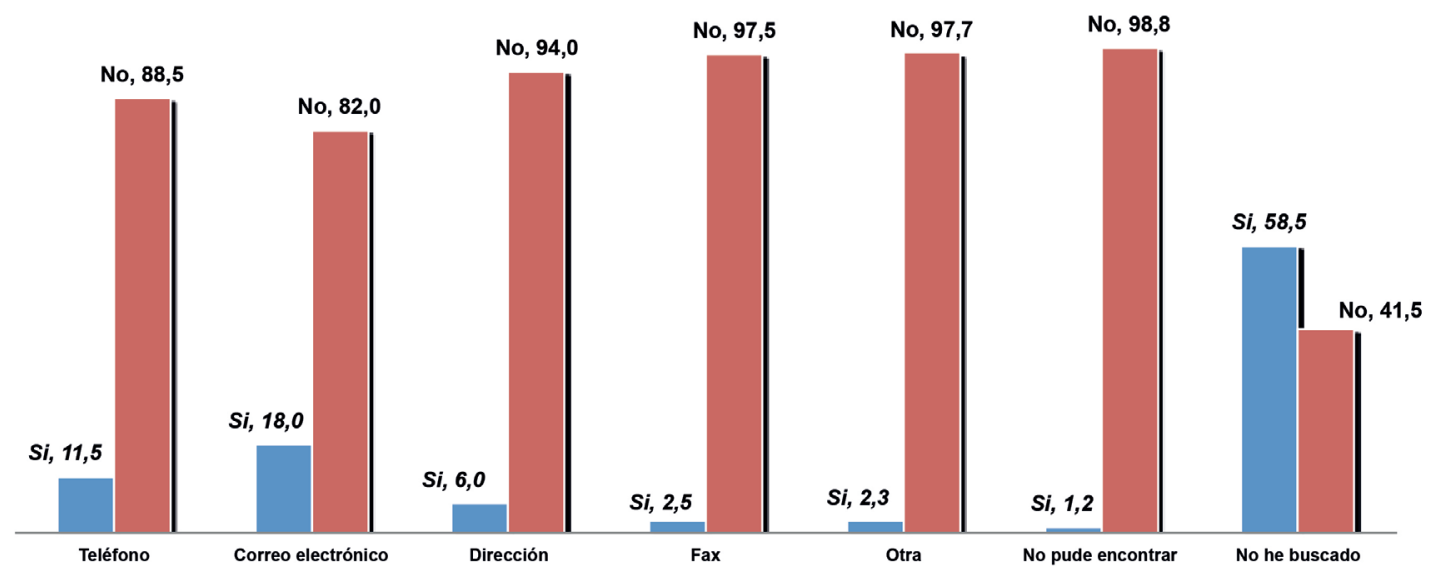

Fuente: Salcedo (2012).

\subsection{Información sobre las Escuelas de Familia}

Para el caso de la información sobre las Escuelas de Familia, los resultados reflejaron un 18,7\% en relación a las actividades a ejecutar por la institución, 12,7\% funcionamiento, $10 \%$ noticias y el 4,4\% inscripciones o afiliaciones, de igual manera se obtuvo nuevamente el mayor porcentaje del $41,2 \%$ a la opción no he buscado (gráfica 8). Sobre la base de lo explicado anteriormente es importante resaltar el hecho que la opción no he buscado, fue la más seleccionada por el público meta al ubicarse en 55,3\% y 41,2\%, ítems 14 y 15 respectivamente.

Gráfica 8. ¿Qué tipo de información encontrada en las páginas web, o Internet, acerca de las Escuelas de Familia?

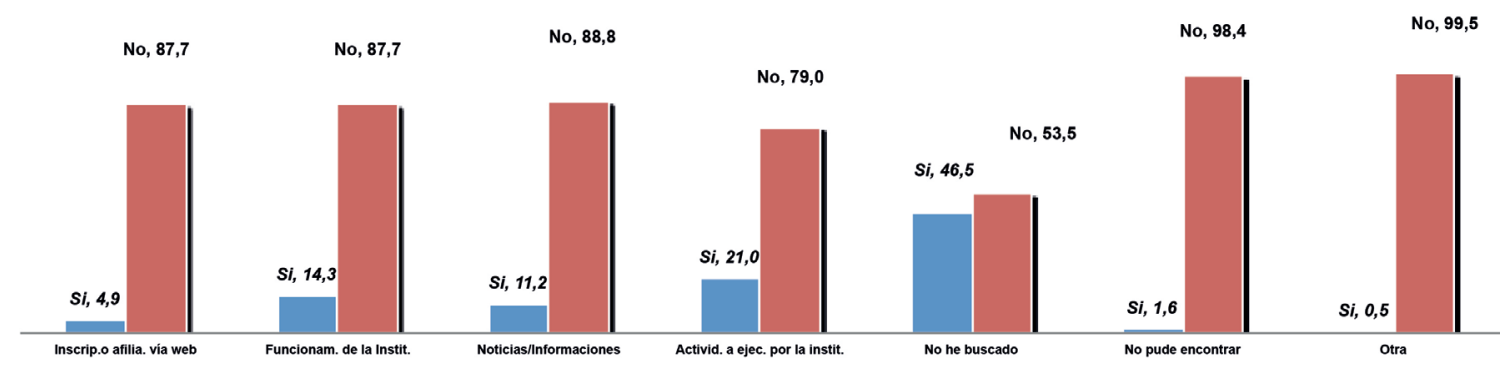

Fuente: Salcedo (2012). 
Dando continuidad a la subdimensión del nivel informativo se encontró que la Escuela o Liceo es una de las plataformas tecnológicas con mayor acceso (38\%), seguida por el Ministerio del Poder Popular para la Educación con 29,5\%, AVEC 18\%, Pastoral Familia 8,8\%, Iglesia 4\%, mientras que la Gobernación y Alcaldía alcanzaron el 2,5\%.

\subsection{Información sobre la evaluación y gestión}

En referencia al indicador Información sobre la evaluación y gestión, los resultados revelaron que cerca a las tres cuartas partes de la muestra (73\%) no buscaron información en sitios web que les permitan evaluar las Escuelas de Familia, el 17,3\% señaló no haber encontrado y un 9,7\% admitió haber encontrado información (gráfica 9).

\section{Gráfica 9. ¿Ha encontrado en las páginas web información que le explique cómo y en qué sitio de internet} evaluar, gratificar o denunciar la gestión de los miembros de las Escuelas de Familia?

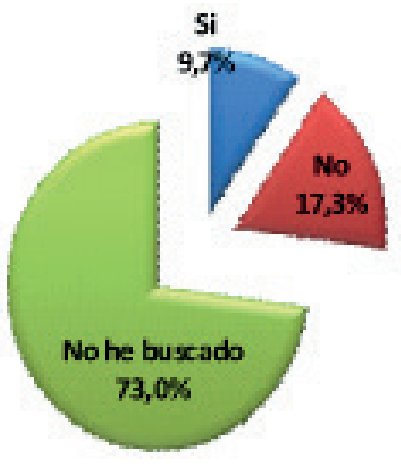

Fuente: Salcedo (2012).

Del mismo modo se observó que las páginas a través de la cual se obtuvo mayor información fue la del Ministerio del Poder Popular para la Educación (33,3\%), La Escuela o Liceo $(23,8 \%)$, Pastoral Familiar y AVEC ( $14,3 \%$ cada una) y con menor porcentaje la Iglesia (9,5\%) seguida de la Alcaldía (4,8\%).

\subsection{Información para ejercer control y fiscalización}

Continuando con el indicador información para ejercer control y fiscalización, el 16,4\% de los encuestados señalaron haber encontrado información referente al uso que los miembros de las Escuelas de Familia hacen de sus recursos para cumplir sus actividades; el 10,4\% no encontraron y nuevamente el factor no he buscado ocupa el mayor porcentaje con $73,3 \%$ (gráfica 10 ). 
Gráfica 10. ¿Las páginas muestran información sobre el uso que los miembros de las Escuelas de Familia hacen de sus recursos para cumplir actividades?

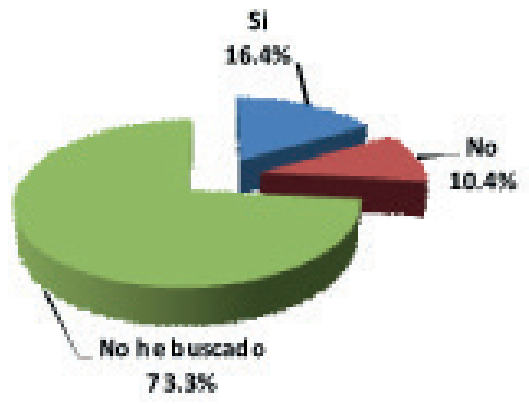

Fuente: Salcedo (2012).

Respecto a la apreciación de la información localizada por los encuestados, el 50,7\% la consideró satisfactoria, el 36,6\% excelente y solo un 12,7\% deficiente. Certificaron que la misma se obtuvo a través de páginas de Escuela o Liceo (26,8\%), Pastoral Familiar (25,4\%), AVEC (23,9\%), Ministerio del Poder Popular para la Educación $(16,9 \%)$ y de forma minoritaria la Iglesia al igual que la Gobernación $(2,8 \%)$ y la Alcaldía (1,4\%). Es de hacer notar que de la información obtenida el 14,3\% reveló cómo formar una Escuela de Familia.

\subsection{Información sobre proyectos}

El resultado del último indicador Información sobre proyectos, analizado para la subdimensión nivel informativo, señala que 17,7 \% encontró explicación sobre proyectos para la formación de miembros de la familia en particular, $17,5 \%$ no encontró y $64,8 \%$ no buscaron (gráfica 11 ).

Gráfica 11. ¿Ha encontrado información en la web, sobre cómo proponer proyectos para la formación de miembros de familia?

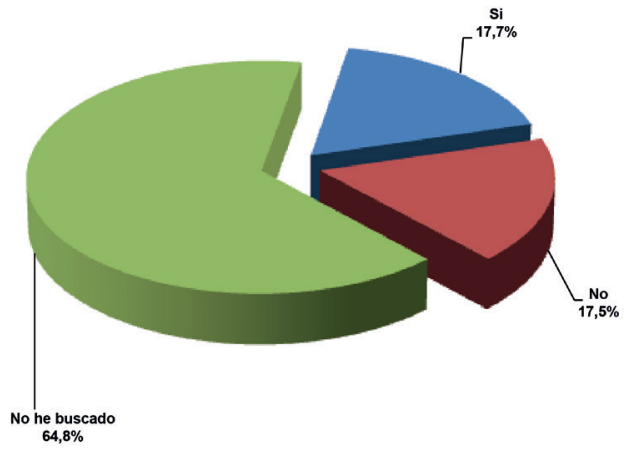

Fuente: Salcedo (2012). 
Dando continuidad a la respuesta afirmativa $24,7 \%$ del total de los encuestados procedieron a proponer algún proyecto; $18,2 \%$ señaló que no le ha servido hasta ahora y $57,1 \%$ no lo han intentado. La mencionada información se obtuvo principalmente por la Escuela o Liceo (31,2\%), Ministerio del Poder Popular para la Educación (23,4\%), AVEC (19,5\%), Pastoral Familiar (15,6\%).

En cuanto al objetivo específico relacionado a describir el nivel informativo en los usuarios de las TIC en las Escuelas de Familia, los ítems distribuidos en siete (7) indicadores muestran que la información abre nuevos horizontes y paradigmas. Una tendencia hacia la integración de los medios teniendo como eje central a Internet. Terán (2011) hace una reflexión sobre el uso de las novedosas tecnologías por parte de los miembros de la familia, considera que es un recurso muy importante para obtener información y comunicarse.

Los resultados revelan que la trascendencia de las novedosas tecnologías y la emergente Sociedad de la Información -SI-, genera oportunidades, es aquí donde se impone lo proyectado por Castells (2003), al hablar de "sociedad informacional", sosteniendo que la información, como comunicación del conocimiento, ha sido parte fundamental de todas las sociedades a través del tiempo y que el término informacional indica el atributo de una forma específica de organización social en la que la generación, procesamiento y transmisión de información se convierten en las fuentes fundamentales de la productividad y el poder; donde se privilegian por momentos la información y el conocimiento para dar paso a la "sociedad red".

La información facilita al ciudadano conocer y disponer sobre derechos, responsabilidades y opciones para el cambio y transformación social. Así, la Contraloría Social del estado de Guanajuato (2006) da fuerza al postulado comunicacional al señalar que la población tiene derecho a ser informada sobre los asuntos públicos, de lo contrario, no podría comprometerse efectivamente si no conoce sobre el tejido público de su comunidad local, regional o nacional.

\subsection{Consultas a usuarios}

Al abordar la subdimensión Nivel de consulta, los resultados obtenidos del indicador consulta a usuarios, se obtuvo que las herramientas de participación más usadas corresponden al foro con el $17,1 \%$ y a la encuesta con el 16,1\%, de igual manera, pero con menor porcentaje, se encuentra el correo electrónico $(10,6)$ y otro con $6,5 \%$; es de hacer notar que la opción "ninguna" es la que ocupa el mayor porcentaje $(49,8 \%)$ revelando que a pesar de existir y contar con las herramientas, los usuarios no hacen uso de las mismas (gráfica 12). 


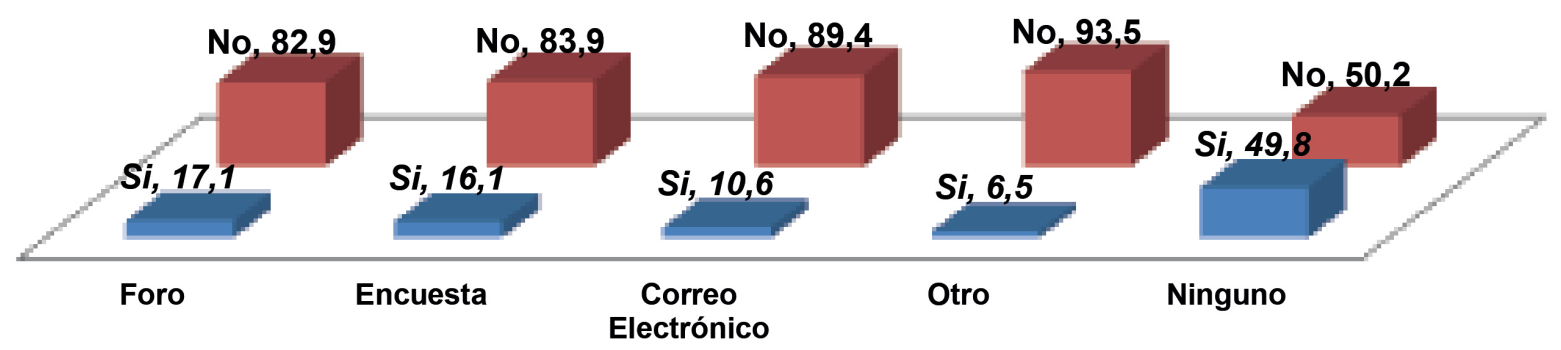

Fuente: Salcedo (2012).

Con base en la participación a través de las herramientas ya detalladas, los participantes pudieron aportar información (29,8\%), recursos para proyectos (25,2\%), evaluación de miembros (19,3\%), evaluación de instituciones $(14,7 \%)$, leyes $(7,8 \%)$ y otra (3,2\%). Para el caso de participación en encuestas, los consultados (44,3\%) respondieron haber visto reflejados los resultados en las plataformas digitales, mientras que otra parte de los encuestados (55,7\%) manifestó que no.

A pesar de que los resultados son bajos en cuanto al nivel de consulta de los usuarios, queda claro que quienes deciden participar lo hacen aportando información y solicitando recursos para las Escuelas de Familia. Surge la necesidad en los niveles de participación planteado por Orregon (en Gobierno de Chile 2001c) a través del cual distingue la consulta como el mecanismo de invitar al ciudadano a opinar. En consecuencia la Contraloría Social del estado de Guanajuato (México, 2006) ofrece a todos aquellos que puedan resultar afectados directa o indirectamente por una decisión gubernamental, el derecho a ser consultados.

Sobre las base de las consideraciones anteriores, el ciudadano, hoy en día, deja de ser un simple "depositario de derechos" y viene a ser un sujeto activo en la implementación de las políticas que lo afectan; busca participar en ámbitos de empoderamiento que va definiendo según su capacidad de gestión, evaluando el ámbito más propicio, según el tipo de demanda que quiere realizar.

\subsection{Respuesta de instituciones}

En cuanto a la participación sobre reclamos y sugerencias a través de la página web en temas ligados a la atención de la familia un 60,6\% de los padres y representantes manifestaron no haber buscado. El 29,5\% no participó y el 9,9\% realizó intervenciones. Entre las dos primeras cifras citadas se evidencia la apatía o indiferencia de los miembros de las Escuelas de Familia (gráfica 13). 


\section{Gráfica 13. ¿Ha hecho Ud. algún reclamo o sugerencia a través de las páginas web} ligadas a la atención de la familia?

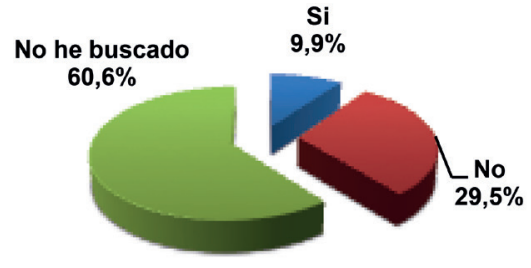

Fuente: Salcedo (2012).

Los padres y representantes que decidieron participar afirmaron haber realizado sus reclamos y sugerencias a través de organismos gubernamentales (34,9\%), por otra parte, el 65,1\% dijeron haberlo hecho por otras vías (gráfica 14). En ese mismo sentido, los consultados calificaron las respuestas de las instituciones del Estado como buena en $48,8 \%$, deficiente en un $39,5 \%$ y excelente $11,6 \%$.

\section{Gráfica 14. ¿En caso de ser positiva su respuesta indique si fue a través si fué a través de organismo gubernamental?}

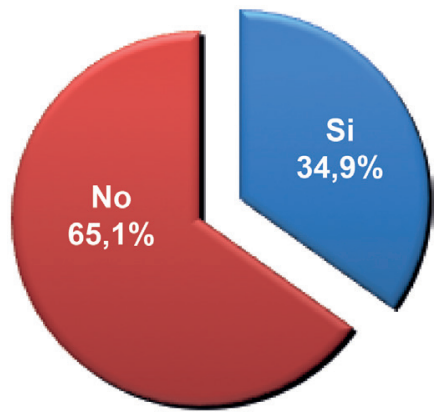

Fuente: Salcedo (2012).

Sobre el indicador respuesta de instituciones ante exigencias los resultados demuestran que un $47,9 \%$ de los padres y representantes no han intentado inscribirse en las Escuelas de Familia a través de Internet; por su parte el 43,6\% no lo ha hecho y el 8,5\% mostró interés al respecto (gráfica 15). 


\section{Gráfica 15. ¿Se ha inscrito en alguna Escuelas de Familia a través de Internet}

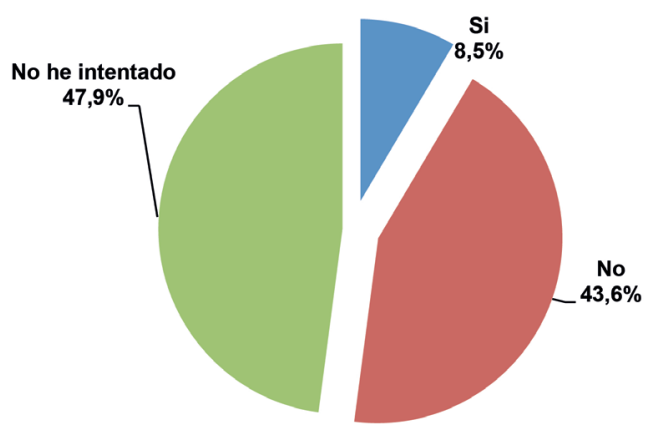

Fuente: Salcedo (2012).

La recomendación para la ejecución de algún proyecto de familia ante diferentes entes gubernamentales utilizando los sitios web alcanzó 7,8\%, mientras que 92,2\% se manifestó indiferente. Ahora bien, del ciento por ciento de los que respondieron afirmativamente la pregunta inmediatamente anterior $29,4 \%$ asumieron el compromiso y $70,6 \%$ restante lo obviaron.

Con respecto a los resultados del objetivo Identificar el nivel de decisión en los usuarios de las TIC, Macías (2009) estima que existe participación en la medida que hay presencia activa de cada ciudadano en la toma de decisiones para la construcción de una mejor sociedad. Es más enfático al suponer una visión de transformación y perfeccionamiento de la misma a través de una promoción del cambio social; en la medida que ocurran alteraciones en las estructuras sociales se encamina hacia al éxito o el fracaso.

En este orden de ideas, el ciudadano deja de ser un simple "depositario de derechos"y pasa a ser un sujeto activo en la implementación de las políticas que lo afectan, busca empoderarse de la gestión y evaluarla. Sin embargo, para ello es necesario que la participación no se quede en simple información ni consultas de opiniones, sino tomas de decisiones compartidas después de un conocimiento, con tiempo suficiente y mecanismos claros de los problemas y de las alternativas sustentables donde los ciudadanos puedan sentirse implicados y responsables.

Sustentan los resultados la teoría del documento de la Contraloría Social del estado de Guanajuato (2006), en cuanto al nivel de decisión, a través del cual persuade al derecho a participar con determinación, donde el nivel de profundidad lo debe ejercer la autoridad, previa información y consulta a la ciudadanía afectada.

\subsection{Control de las EF}

De acuerdo con el razonamiento que se ha venido desarrollando y para afianzar el análisis, se aborda la subdimensión nivel de control con un primer indicador solicitud de información que permitió detectar el tipo de información solicitada por los encuestados a las Escuelas de Familia, encontrando que el mayor porcentaje es para la opción ninguna con 46,3\%, le siguen desarrollo de actividades con 28,1\%, informe de gestión 23,3\% y otras 2,3\% (gráfica 16). Ahora bien, las mencionadas solicitudes las realizaron a través de otra (reunión) en un $75,5 \%$, foros $16,7 \%$ y con un $7,7 \%$ correos electrónicos. 


\section{Gráfica 16. ¿Qué tipo de información ha solicitado usted a las Escuelas de Familia}

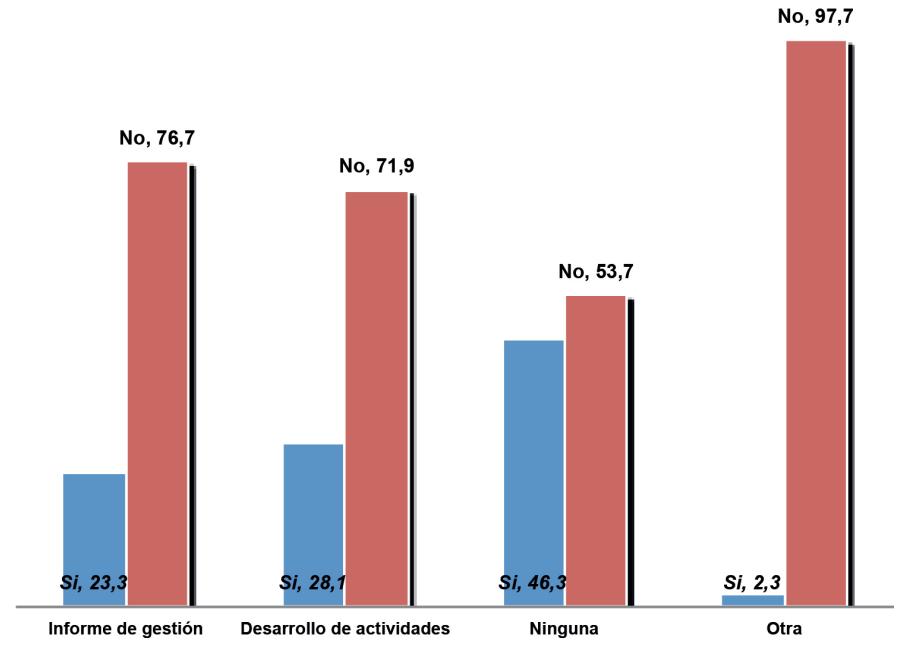

Fuente: Salcedo (2012).

En ese sentido, se encontró que 40,8\% de las solicitudes fueron respondidas, y que las mismas solicitudes se efectuaron a través de las páginas de escuelas o liceos (41,1\%), Ministerio del Poder Popular para la Educación $(30,5 \%)$, otra -reunión- (22,1\%), seguida por la respuesta no recuerdo y AVEC (4,2\% y 2,1\% respectivamente).

\subsection{Denuncias a miembros y directivos}

Después de las consideraciones anteriores relacionadas con la subdimensión nivel de control, se continúa con un segundo indicador denuncias a miembros y directivos, en el cual en la gráfica 14 se plasma que 9,9\% de la población muestral ha realizado denuncias de miembros o directivos de una Escuela de Familia por medio de plataformas virtuales, $79,7 \%$ señaló que no y $10,4 \%$ no sabe/no responde (gráfica 17 ).

Gráfica 17. ¿Ha denunciado a través de plataformas virtuales (Internet) a miembros directivos de una Escuela de Familia?

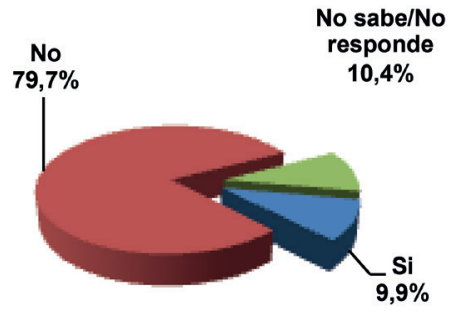

Fuente: Salcedo (2012). 
En relación a la respuesta afirmativa se evidenció que las irregularidades fueron denunciadas en su mayoría vía Facebook 55,8\%, otro 16,3\%, correo electrónico $14 \%$ y a través de Twitter y foros $7 \%$ cada uno. A los efectos de esperar respuesta solo $14 \%$ fue atendido, $27,9 \%$ no sabe y $58,1 \%$ no recibió ninguna respuesta a su planteamiento.

De la misma manera los encuestados se manifestaron en cuanto a la respuesta gubernamental, señalando un $44,2 \%$ como buena, $34,9 \%$ no cumple con mis expectativas y $20,9 \%$ muy satisfactoria. Cabe agregar que los consultados apuntaron en un $44,2 \%$ que prefieren realizar las denuncias por páginas de instituciones privadas, $37,2 \%$ a través de organismos oficiales y $18,6 \%$ seleccionó la opción otra.

Sobre la base de las consideraciones anteriores se evidenció que los miembros de las Escuelas de Familia no manejan información suficiente que les permitan controlar las actividades de la mencionada organización familiar.

Para fundamentar estos resultados Tissenn (2005) manifiesta que las TIC constituyen una respuesta a las necesidades de la sociedad. Su rol se centra en las actividades informacionales de todos los individuos que de una u otra forma utilizan sus capacidades técnicas para sintetizar las funciones que anteriormente eran tratadas de manera manual, visualizando como eje central de su progreso la sistematización técnica de la información y el conocimiento.

Aun cuando los resultados reflejaron poco o escaso control por parte de los miembros de las Escuelas de Familia acerca de las actividades que le rigen, la tesis de la Contraloría Social del estado de Guanajuato (2006) referente al control, especifica el derecho de los ciudadanos a ejercer acciones de fiscalización social sobre la gestión pública, ya que una vez tomada la decisión, se requiere también de mecanismos que permitan su verificación y cumplimiento.

\subsection{Actividades y proyectos}

Para la interrogante $¿$ Ha propuesto usted algún proyecto a través de las páginas web, para que este sea ejecutado por la Escuela de Familia?, insertada en subdimensión nivel de ejecución del indicador actividades y proyectos enmarcado en la dimensión niveles de participación, el resultado arrojado fue que $88 \%$ no planteó proyecto alguno, solo $12 \%$ respondió afirmativamente (gráfica 18 ).

Gráfica 18. Propuesta de proyectos a través de páginas web

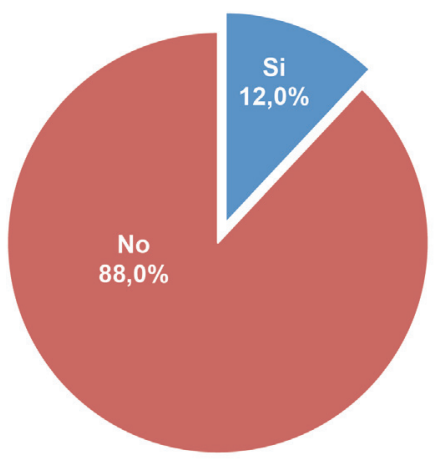

Fuente: Salcedo (2012). 
Ahora bien, basado en los 52 encuestados (12\%) que sugirieron proyectos a través de la página web, 5,8\% fueron aprobados y $1,9 \%$ rechazados, mientras 30,8\% manifestó no haber obtenido respuesta y $61,5 \%$ alegó no saber. De igual manera aseguraron haber realizado propuestas utilizando las páginas web de la pastoral familiar en un 23,1\%, de escuela o liceo 15,4\%, en igual porcentaje (9,6\%) a través del Ministerio del Poder Popular para la Educación, la Iglesia y el AVEC; con 3,8 \% la Alcaldía, 7,7 \% por otra vía y, finalmente, 21,2\% indicó no recordar.

De lo anteriormente planteado se desprende que los padres y representantes no están aprovechando las bondades que ofrecen las novedosas tecnologías de la información y la comunicación para proponer proyectos para las Escuelas de Familia que contribuyan al desarrollo de esas instituciones que redundarían en el beneficio de la escuela, el estudiante y la comunidad.

En relación al objetivo específico referido a caracterizar el nivel de ejecución en los usuarios de las TIC en las Escuelas de Familia de los colegios católicos de Maracaibo, estado Zulia, los resultados arrojaron que sigue en decrecimiento la participación ciudadana, específicamente en cuanto a la propuesta de proyectos a través de las páginas web. En contraposición a esa situación Sánchez (2008) señala que las TIC deben aprovecharse para el desarrollo integral de una comunidad, con visión integral de desarrollo, sobre todo, que impulse el potencial humano en sus diferentes dimensiones para afianzar así la prosperidad económica, pero con equidad, y el fortalecimiento democrático con transparencia y justicia social.

Sobre la base de las consideraciones anteriores, se exhorta al ciudadano a ser un sujeto activo, apropiarse de las TIC como herramienta eficaz para el fortalecimiento del aprendizaje social para la transformación de su comunidad, en este caso de las Escuelas de Familia.

Aún cuando se registró poca participación de los padres y representantes, en cada uno de los niveles, se evidenció la teoría de Albornoz (2007) quien manifiesta que la participación ciudadana está dando sus primeros pasos hacia la e-participación, delineando características y exigencias propias; todo producto de la iniciativa propia desde los distintos escenarios de acceso, conectividad y empoderamiento de las herramientas tecnológicas, organizándose, pasando de usuarios a actores capaces de generar un nuevo tejido social y una nueva realidad al margen de la voluntad inicial del Estado o de las propias organizaciones de la sociedad civil.

\section{Conclusiones}

Los procesos de incorporación de las Tecnologías de Información y Comunicación a las organizaciones exhiben un alto grado de complejidad. El ciudadano y las organizaciones actuales se socializan en un contexto de gran desarrollo de las novedosas tecnologías, y eso facilita que estén familiarizados con el lenguaje y los formatos de las TIC, y sientan atracción por interactuar en este medio.

Como resultado de analizar la participación ciudadana a través de las TIC en las Escuelas de Familia en los colegios católicos de Maracaibo, estado Zulia, cuya dimensión niveles de participación que constituye todo el objeto de estudio, se exponen las conclusiones generales, en función de cada uno de los objetivos específicos planteados.

En lo que respecta a describir el nivel informativo en los usuarios de las TIC, relacionado a la subdimensión nivel informativo, a pesar de tener Internet como eje central los resultados reflejaron que existe una escasa apropiación tecnológica orientada a conocer las actividades y gestión de las organizaciones familiares; además es muy elevado 
el desinterés por buscar documentos legales, contactar a otros miembros e instituciones públicas o privadas para el mejor aprovechamiento y participación de los miembros de las Escuelas de Familia.

Como consecuencia de esto, los usuarios desatienden el atributo de una forma específica de organización social en la que la generación, el procesamiento y la transmisión de información se convierten en las fuentes fundamentales de la productividad y el poder de las Escuelas de Familia, facilita al ciudadano conocer y disponer sobre derechos, responsabilidades y opciones para el cambio y transformación social.

En cuanto a identificar el nivel consultivo en los usuarios de las TIC en las Escuelas de Padres de los colegios católicos de Maracaibo, estado Zulia, se midió la subdimensión nivel de consultas, demostrando que la mayoría a pesar de contar con las herramientas tecnológicas de participación no hacen uso de las mismas.

Continuando con los hallazgos de esta investigación, en lo referente a describir el nivel de decisión en los usuarios de las TIC, se evidenció apatía o indiferencia en la participación, en cuanto a afiliación, reclamos, sugerencias o ejecución de proyectos de familia. La negativa de los ciudadanos en sentirse implicados y responsables, además, no se persuada del derecho a participar con determinación y presencia activa en la toma de decisiones, aleja la posibilidad de promover un cambio social para construir una mejor sociedad

En referencia a estudiar el nivel de control en los usuarios de las TIC, en la subdimensión nivel de control, a través de la cual se examinaron los indicadores solicitud de información y denuncias a miembros y directivos se evidenció que los miembros de las Escuelas de Familia no manejan información suficiente que le permita controlar las actividades de la mencionada organización familiar.

En relación al último objetivo relacionado caracterizar el nivel de ejecución en los usuarios de las TIC, bajo la subdimensión nivel de ejecución se desprende que los padres y representantes no están aprovechando las bondades que ofrecen las tecnologías de la información y la comunicación para proponer proyectos para las Escuelas de Familia que contribuyan al desarrollo de esas instituciones y redunden en el beneficio de la escuela, el estudiante y la comunidad.

Se observa claramente que sigue en decrecimiento la participación ciudadana, sin que se aprovechen las tecnologías de información y comunicación para alcanzar objetivos, unir esfuerzos comunitarios, ponerse en red en aras del desarrollo, impulsar la participación comunitaria en la gestión de la institución, aumentar los grupos virtuales de ayuda mutua, fomentar la cultura, entre otras ventajas.

En cuanto al objetivo general, cuyo fin fue analizar la variable participación ciudadana a través de las TIC en las Escuelas de Familia en los colegios católicos de Maracaibo, estado Zulia, sobre la base del análisis e interpretación de los resultados expuestos ampliamente y las conclusiones obtenidas de los objetivos específicos, se puede afirmar que a pesar de contar con las herramientas tecnológicas, la mayor participación se manifestó en el nivel informativo, aún cuando los padres y representantes lo hacen para involucrarse en actividades no pertinentes a la organización que les agrupa. En ese mismo orden, se observó presencia poco significativa en el derecho a participar en la toma de decisiones, control y ejecución de actividades, alejándose la posibilidad de promover un cambio social para construir una mejor sociedad.

En consecuencia, no basta solo con tener las novedosas tecnologías de información y comunicación, sino darle uso con sentido, ubicarlas en la dimensión de importancia que tienen para la vida cotidiana, fundamentalmente en la Escuela de Familia de los colegios católicos, como centro experimental de la investigación. El uso social de 
las TIC implica conocerlas y emplearlas, destinarlas a diversas tareas, trascendiendo las posibilidades de comunicación y desarrollo de habilidades para la estructuración del conocimiento.

Debido a esto, la construcción de la identidad virtual de los padres es fundamental en el desarrollo de estrategias para el trabajo colaborativo que permita, entre otras cosas, identificar, evaluar, compartiry diseñar materiales en colaboración con el resto de personas incluidas en las Escuelas de Familia, donde la e-participación promueva el involucramiento más directo de los padres y representantes en los procesos de toma de decisiones.

\section{Referencias}

1. Albornoz, B. (2007). Experiencias andinas de gobierno electrónico: La problemática de la participación ciudadana (1ra. Ed.). Versiones de gobierno electrónico implementadas en el Municipio de Quito. Quito, Ecuador: Rispergraf - FLACSO.

2. Castells, M. (2002) La galaxia Internet. Reflexiones sobre Internet, empresa y sociedad. Barcelona, España: De bolsillo.

3. Contraloría social del estado de Guanajuato (2006). Programa estatal de Contraloría Social. Obtenido del portal de la Contraloría Social del estado de Guanajuato, Guanajuato, México. Recuperado el 15 de abril de 2011, de http://sgp.guanajuato.gob.mx/PortalSGP/Upload/ProgramaEstataldeContralor\%C3\%ADa SocialPECS.pdf

4. Del Búfalo (2005). Economía del conocimiento. Recuperado el 20 de octubre de 2012, de http://www.ceiich. unam.mx/pdfp/432.pdf

5. Escuelas de Familia (s.f). Recuperado el 25 de octubre de 2012, de http://www.escuelasdefamilias.com/ pag1.html

6. García, S. (2009), Escuelas para padres, 50 años después. Buenos Aires, Argentina: Editorial Lumen Humanitas.

7. Guillen, A., Sáenz, K., Badii, M., Castillo, J. (2009). Origen, espacio y niveles de participación ciudadana. Daena: International Journal of Good Conscience. Recuperado el 25 de julio de 2012, de http://www. spentamexico.org/v4-n1/4(1)\%20179-193.pdf

8. Hernández, M. \& Solano, I. (2006). Una escuela de padres sobre las TIC y la seguridad en los menores. Actas II Jornadas Nacionales TIC y Educación TICEMUR Valencia, España: Generalitat valenciana.

9. Mas, M. (2007) Desarrollo Tecnoendógeno. Ensayos sobre tecnología y desarrollo endógeno. Caracas, Venezuela: Editorial Panapo de Venezuela.

10. Molina, R. \& Amela, M. (2009). La escuela y las tecnologías. Recuperado el 27 de septiembre de 2010, de http://www.scribd.com/doc/19373453/LA-ESCUELA-Y-LAS-TECNOLOGIAS

11. Merino, M. (1996). La Participación Ciudadana en la Democracia. Quito, Ecuador: Ediciones ILPES, CEPAL.

12. Ministerio del Poder popular para la educación (2007). Sistema de Educación Bolivariano, SEB. Sistematización de nuevos aportes programados para el 20 de agosto de 2007. Dirección General de Currículo. Venezuela.

13. Ministerio del Poder popular para la educación (2005). Resolución 572. Sin publicación en gaceta oficial. 
14. Ministerio de Educación (1999). Reglamento General de la Ley Orgánica de Educación. Gaceta Oficial No. 36787 de fecha 15 de septiembre de 1999. Decreto No. 313.

15. Pitalúa, V. (2008). Nuevas herramientas para la participación ciudadana. Centro de documentación, información y análisis -CEDIA-. Servicio de investigación y análisis - SIA- Universidad Autónoma de Nuevo León -UANL-Centro de Estudios Parlamentarios - CEP-. España.

16. Polanco, X. (2006). Análisis de redes: una introducción. En Albornoz, M. \& Alfaráz, C. (editores): Redes de Conocimiento, construcción, dinámica y gestión. Buenos Aires, Argentina: RICYT.

17. Salcedo, C. \& Páez, A. (2013). Acceso a las TIC en los usuarios de las Escuelas de Familia. Recuperado el 10 de febrero de 2015, de http://www.congresoinvecom.org/index.php/invecom2013/INVECOM2013/paper/ viewFile/436/329

18. Sánchez, M. (2005). Glosarios de términos educativos Venezuela. Valencia, Venezuela: Cardidus Editores.

19. Sánchez, E. (2008). Las Tecnologías de Información y Comunicación (TIC) desde una Perspectiva Social. Revista Electrónica Educare, 12, 155-162. Recuperado el 12 de mayo de 2011, de la base de datos de la Universidad Nacional. Costa Rica, de http://redalyc.uaemex.mx/src/inicio/ArtPdfRed. jsp?iCve $=194114584020$

20. Tendencias digitales (2012). Estudio: La penetración de internet en Venezuela. Recuperado el 10 de junio de 2012, de http://tendenciasdigitales.com/1433/la-penetracion-de-internet-en-venezuela-alcanza-40de-la-poblacion/

21. Terán, F. (2011). ¿Qué actitud y precauciones han de tener los padres y madres con el uso que sus hijos e hijas hacen de internet? Escuelas de Familia. Servicios Sociales del Ayuntamiento de Tarifa. Recuperado el 25 de mayo, de http://www.escuelasde-familia.blogspot.com/

22. Tirado, C. \& col. (2008). Análisis sobre el uso de la tecnología de información y comunicación utilizada para fines académicos por los estudiantes de Comunicación Social de la Universidad Rafael Belloso Chacín. Trabajo de grado. Maracaibo, Venezuela.

23. Tissen, R \& col. (2005). El conocimiento para aumentar en las empresas. Madrid, España: Editorial Prentice Hall.

24. Vásquez, D (2002). Bases de la Teleinformática. Caracas, Venezuela. Recuperado el 18 de mayo de 2010, de www.monografias.com 